I should be sorry for your readers to suppose that I intended to question the wislom of the abandonment of quarantine in England, and I ask you to allow me to quote the words I nsed :- "The practical objection to quarantine is that it cannot be effectually carried out. Even in countries which have little commercial spirit, and amongst the inhabitants of which there is no markedly hostile protest against the great loss of time which quarantine naturally causes, it has been found that the system is practically of little or no value in the prevention of the spread of such a disease as cholera. There is little, therefore, to commend the system to us, and the President of the Local Government Board was decidedly right in his decision to decline to adopt it this year in the case of ships coming from infected ports. The wisdom of this decision is, I think, "enerally admitted. But, if it were not admitted, let us consider for a minute what would happen if a system of quarantine were adopted. This year, it must be remembered, the infected ports were those of Russia and of Germany. Let us suppose that next year those of France were affected. What would happen to our commerce if all communication were cut off from French ports and if passengers from Calais and Boulogne were quarantined? Practically quarantine could not be effectively carried out."

I am, Sirs, yours faithfully,

York-st., Portman-sq., Dec. 19th, 1892. RICHARD SISLEY.

\section{"TREATMENT OF OPHTHALMIA AMONGST THE CHILDREN OF THE POOR."}

\section{To the Editors of THE LANCET.}

SiRs,-My attention has been called to Dr. Jacob's letter in your issue of the 10th inst. That gentleman appears to labour under a complete misapprebension with regard to the steps which have been taken to deal with ophthalmia in some of the London parochial schools. Before entering his "protest" against (what he is pleased to term) "the fashionable system of boxing up a crowd of cachectic children in a special isolation hospital," Dr. Jacob should have made sure of his facts. The confusion in his mind seems to have arisen from the assumption that isolation involves a kind of imprisonment. Since the isolation carried out at the Norwood and Hanwell schools was confided to my hands, I may be permitted to explain to Dr. Jacob the real facts of the case. Most reasonable persons will admit that to allow children with a contagious disease like ophthalmia to have washing and sleeping arrangements in common with unaffected children would be to fly in the face of Providence and court the danger of an extensive epidemic. It may reassure Dr. Jacob to learn, however, that as part of the system, special arrangements have been made for a large amount of outdoor exercise at Hanwell. Every child, for instance, is compelled to walk for two hours each day beyond the precincts of the ophthalmic school. Further, football is compulsory for the boys, while hockey is played energetically by the girls Dr. Jacob will therefore see that a course of open-air treatment is carried out systematically at Hanwell. The "farinaceous dietary" be so strongly recommends is replaced by a liberal diet-table arranged on a somewhat more comprehensive and scientific basis. So far, then, the ground is to a certain extent common between us. As to the "little local treatment to the conjunctiva," of which Dr. Jacob speaks, I can only say that I have found after a somewhat lengthened experience of the disease that months or even years of systematic care are required to effect a cure in cases of severe trachoma.

Dr. Jacob takes it for granted that affected children are

"kept under subjection to all the paraphernalia of green shades, darkened windows, compress bandages \&c." Dr. Jacob may be perhaps astonished to learn that no dark room exists at Hanwell, and that the employment of even a shade for the eyes is an event of some rarity. As for compress bandages, such appliances are most unsuited for cases of trachoma, and indeed for conjunctival affections in general. The statement made by Dr. Jacob, that "infectious granular ophthalmia is, par excellence, the disease of Ireland," will not surprise English readers who have perused his views on the treatment of that affection.-I am, Sirs, yours faithfully,

Sydney Stephenson, M.B.Edin. \&c.

\section{"EXPERIMENTS ON ANIMALS."}

To the Editors of THE LANCET.

SiRs,-The question of whether or not the peritoneum of the human being is sensitive or not is not one which can be settled by experiments on animals; and if my views prove to be correct it only affords another illustration of the misleading nature of the experiments $I$ condemn. If there is an error on my part, it of course must be in my erroneous interpretation of phenomena yielded to me by 3300 human peritoneal cavities. But I am collecting evidence on the subject from other surgeons, and I shall send you the conclusions summarised from that evidence when it is complete I confess at present as I read Dr. Sherrington's letter I can hardly believe that my eyes convey the truemeaning of his words, so absurd do they seem to me.

I am, Sirs, yours faithfully,

The Crescent, Birmingham, Dec. 18th, 1892. LAWSON TAIT.

\section{SUBCUTANEOUS SUTURE OF THE PATELIA.} To the Editors of THE LANCET.

SiRs,-Please cermit me to correct a statement in the account of my instruments for bone suture in your issue of Dec. 10th. Dr. D. W. Aitken's instrument described in my paper as a long bradawl perforated at the end is really a tubular bradawl. 1 The perforated instrument was originally described by Ceci of Genoa in the Deutsche Zeitschrift für Chivurgie, Bd. xxiii., p. 285. A brief extract of this paper in the Centralblatt fiur Chirurgie for Aug. 14th, 1886, treats it with unmerited contempt and gives a wrong reference to it-viz., Bd. xxxii. instead of Bd. xxxiii. I am, Sirs, yours truly,

C. B. KeETLey, F.R.C.S.Eng.

Grosvenor-street, W., Dec. 21st, 1892

\section{NITROUS OXIDE GAS.}

\section{To the Editors of THE LANCET.}

SrRs, - It is in the experience of most if not all administrators of nitrous oxide gas to find the gas obstructed during its exit from the bottle, and on the tap being further unscrewed for the gas to rush out sometimes to an uncontrollable extent, blowing off or bursting the india-rubber connexion, causing great annoyance to the administrator and serious alarm to the patient. This obstruction is said to occur when the bottles are in the horizontal position and to prevent it taking place, the late Dr. Sheppard, anæsthetist to Guy's Hospital Dental School, invented an ingenious contrivance. As, however, the cause of this obstruction is not generally known and so easily prevented I venture to state the reason and remedy for it. It is due entirely to a small quantity of water accumulating from several fillings of the bottles the result either of the condensation of moisture from improperly dried gas or introduced in the process of pumping the gas into the bottles. When this water freezes on account of the absorption of heat which takes place during the changing of the liquid gas into the gaseous condition, it forms an effectual barrier to the outward flow of the gas which may suddenly yield as the tap of the bottle is further unscrewed. The remedy is a simple one and is in the hands of the manufacturers of the gas or of those administrators who have their own bottles refillednamely, taking the precaution to have the taps of empty bottles removed and the water shaken out. I have adopted this plan for two years, during which time I have experienced. no inconvenience in administering nitrous oxide gas from bottles placed in the horizontal position.

I am, Sirs, yours truly,

S. EdwaRd Pediey, M.R.C.S., L.R.C.P. Lond. Anæsthetist to the National Dental Hospital.

The Terrace, Camberwell, S E., Dec. 19th, 1892.

\section{"ON THE DIAGNOSIS OF THE DIFFERENT"} FORMS OF PROSTATIC ENLARGEMENT."

\section{To the Editors of THE LANCEN.}

Sins, - It is allowable to the profession, I presume, to succinctly criticise any article dealing with matters of importance in your valuable journal; at least such have been 